\title{
Relation among Food Habit, Morbidity and Mortality
}

\author{
M Ashraful Kabir \\ Department of Biology, Saidpur Cantonment Public College, Nilphamari, Bangladesh \\ *Corresponding Author: M Ashraful Kabir, Department of Biology, Saidpur Cantonment Public \\ College, Nilphamari, Bangladesh
}

\begin{abstract}
Human ancestor noticed that once a time human had very long digestive system which leads to digest vegetables. That time hunting was so complicated that people didn't get meat. Plant cultivation was easy so they took mainly plants as their regular food. For the time being people was known about food and nutrition. At present lot of research are still going in various sections on human health. Several reports suggest that the longevity of vegetarians is 3.6 years higher than meat eaters. People may live smoothly without taking any animals with higher lifespan (Table 2 and 6). Peoples take meat only for their prehistoric practice. Moreover, we can't get taste of fat but most people like to take meat. Some study suggests that only for vitamin $B_{12}$ we must take animal. But recently we have found this vitamin in coconut milk, almond milk, Chlorella, microorganism and soy products. Animals which are in more sleep not live longer (Table 7). From all research this is clear that there is a relation between food habit and mortality in human or other animals.
\end{abstract}

Keywords: Human origin; Food habit; Mortality.

\section{SUMMARY}

Lot of research noticed that there were relation between food habit and mortality. Human takes plants and animals as food. Depending on food chain all animals are surviving into three categoriesherbivore, carnivore and omnivore. Longevity of herbivore animals is higher than carnivore. Tiger, Lion and Hyaena have only 10 years life span but when it's kept in zoos its longevity observed 20 years. In zoos, vitamin supplement is applied through food or directly injection and better treatment all are the factors for its long lifespan. Crocodile or its allies in wild lifespan is only 45 years plus but in zoo this is 100. Large whale and tortoise is mainly herbivore; its lifespan are 80 and 150 years respectively. In zoos/research centre/captivity tortoises' lifespan was found 255 years (Table 5). Man in omnivore. Their long digestive system proves that ancient man was herbivore. For the course of time lives in different regions in different climate man have habituated to take all things especially meat. Modern research is always saying that meat or red meat is bad for health. Now peoples know everything through the subject 'Food and Nutrition'. Moreover, our developed brain is always alarming us to do the best thing. Al- Tabari lived 84 years. He has understood in his time that red meat is bad for health. The father of western medicine 'Hippocrates' mentioned that which was good food for health. It's really proven that scientific lifestyle increases our longevity. In Bangladesh though our longevity is now 70.8 years but this is not for consciousness; this is based on excellent treatment of the diseases (Table 1, 2, 3 and 4). Japanese peoples' lifespan is higher all over the world (84 years). Their staple food is rice but their rice taking style is different than Bangladeshi people. They make rice curry and soup with some sea food and mostly vegetables. Italy, Greece, Sweden and Spain all have higher lifespan with staple food rice but their food taking style is similar with Japan (Table 2). Moreover, most of the countries they have tradition of exercise. In Bangladesh most people perform exercise after affecting disease. This is completely a wrong system which is still going on. They run after detects of diabetes mellitus, they take less salt/sugar after heart diseases, less spicy after acidity etc. If a diabetic patient wants to keep fit and he/she takes exercise or heavily controlled their glucose may fall zero and this may causes for heart attack. Ill health is not good for exercise. We should ensure the sound health and remember prevention is better than cure. From the very beginning people were very industries and that time no exercise system was found. Now we have invented yoga, 
meditation (modern yoga), gym, free-hand exercise etc. Now peoples have known that health is wealth. A sound health is our main achievement among all. African Elephants' longevity is 70 years. Elephant is herbivore. It not takes chicken, egg, milk, fish and beef throughout their life. Cow is herbivore animal. After slaughter we find huge fat. Where from this fat comes? Only from plants. So, if we take only fruits and vegetables we will get all things. From sweet fruits (most fruits are sweet) we get glucose, protein from pulses and oil from bran, underground fruits contain minerals, common fruits are full of vitamin and most juicy fruits and vegetables are completely full with huge water (Table 3 and 4). Hippocrates said that walking is man's good exercise. So, science or scientific application is very primitive. From USA and Indian Mughal emperor we have habituated to take rich and fast food. We have only four types of taste bud- sweet, biter, sour and salt. Here only sweet is pleasant taste whereas others are unpleasant. We have no taste bud of oil and hot. So, hot and oil is our abnormal taste. Peoples take cigarette and betel leaf with accessories which have no taste. Rice has no taste that's why we take all things with rice. Domestic animals like cow, goat, sheep and pig are less active and in preserve bad fat for human. In nature which animals have hardy armour, less predators and island dwellers are getting advantage to live longer. Animals which sleep more not show higher longevity (Table 7). Ram Dev of India who is now a great yogist says that animals are not good for health. Shilpa Shetty is a famous Indian film actress who is a student of Ram Dev, maintains yoga and crash diet for her life. Bruce Lee was a great martial art hero of China habituated to take Chinese traditional dish. Jackie Chan another famous martial art hero takes good food and if takes excess food do extra walk. Famous peoples maintain their private dietitian and beautician. So, if we take more plants in scientific way of course our longevity will increase. By studying anthropology, evolution, history, medical science, biology, food and nutrition, philosophy and sports biology indicating that plants eater are surviving higher than meat eaters.

\section{INTRODUCTION}

From the fossil record we have known about Paleolithic human who survived 2.6 million years ago. They used stones as a tool. Meat was an example of a direct product comes from hunting animals. Milk from mammary gland, eggs from bird and honey from bees from flowers were popular sweetener in many cultures. Some cultures took blood sausage as a thickener for sauces, cured for disease, and others use blood in stews. Some cultures and people didn't consume meat or animal food products for cultural, dietary, health, ethical, or ideological reasons. Vegans didn't consume any food from animals. Human diet was estimated to cause cancers (35\%) (Richard Doll and Richard Peto, 1981).Corn and peanuts contaminated with fungus (mycotoxins, aflatoxins). Other carcinogens identified in meat when cooked at high temperature, smoked fish, and nitrosamines generated from nitrites used as food preservatives in cured meat such as bacon. Anticarcinogens that may help to prevent cancer can also be found fruits and vegetables. Antioxidants are important groups of compounds that may help remove potentially harmful chemicals. Others choose a healthier diet, avoiding sugars or animal fats and increasing consumption of dietary fiber and antioxidants. Obesity, a serious problem in the western world, leads to higher chances of develops heart disease, diabetes, cancer and many other diseases. Deficiencies, excesses, and imbalances in diet may produce negative impacts on health which lead to scurvy, obesity, osteoporosis, diabetes, cardiovascular diseases as well as psychological and behavioral problems. The science of nutrition attempts to understand how and why specific dietary aspects influence on health.

Historians agree that Hippocrates was born around the year 460 BC on the Greek island of Kos. Soranus wrote that Hippocrates's father was Heraclides who was a physician and his mother was Praxitela. Hippocrates learned medicine from his father and grandfather (Hippocrates I). Hippocrates died, probably in Larissa, at the age of 83,85 or 90 , and some say he lived over 100. Hippocrates is credited to believe that diseases were caused naturally, not because of superstition and gods. He separated the discipline of medicine from religion, believing and arguing that disease was not a punishment by the gods but rather the product of environmental factors, diet, and living habits. Ancient medicine at the time of Hippocrates knew almost nothing of human anatomy and physiology because of the Greek taboo forbidding the dissection of humans. The Hippocratic School achieved greater success by applying general diagnoses and passive treatments. French physician M. S. Houdart called the Hippocratic treatment a 'meditation upon death. Hippocrates is given credit for the first description of clubbing of the fingers (Hippocratic fingers). Hippocrates began to categorize illnesses as acute, chronic, endemic and epidemic. Hippocrates often used lifestyle modifications such as diet and exercise to treat diseases such as diabetes, what is today called lifestyle medicine. He is often 
quoted with "Let food be your medicine, and medicine be your food" and "Walking is man's best medicine.

Al-Tabari was born in $839 \mathrm{AD}$ was attentive to his health, avoiding red meat, fats and other foods he deemed unhealthy. He was seldom sick before his last decade when he suffered from pleurisy. When he was ill, he treated himself (to the approval of physicians). His daily routine was- rising early for prayer, studying until early afternoon, reciting Qur'an and teaching Qur'an, and then teaching law until late. He died at age 84 years in Baghdad in 923 AD.

In Hindu religion foods are of three types- Tamasic foods are those that have a sedative effect on the mind and body. In general, they are considered detrimental. Meat of an animal, fish, the fertilized egg, onion, garlic, scallion, leek, mushroom, alcoholic beverages, cheese, eggplant, opium and any food which has been kept overnight before consumption. Rajasic foods are those that have a stimulating effect on the mind and body. They are considered to be neither beneficial nor harmful, and are often obtained in a way that harms another organism. Coffee, tea, cola drinks, energy drinks, chocolate, overly spicy food, salty food, and the unfertilized egg. Only Sattvic foods are acceptable as offerings to the Hindu gods, with rare exceptions. Water, cereal grains, legumes, vegetables, fruits, nuts, unpasteurized and unhomogenized fresh milk and all fresh milk derivatives (mostly ghee, but also butter, cream, fresh or cottage cheese (paneer), and yogurt (lassi)), and raw honey. Eggs are a very complicated case and don't have a clear cut answer. Since there's debate as to the validity of the sources that categorize it as Tamasic or Rajasic.

\section{Methodology}

My experiences on human food habit of my all relatives, friends and colleagues. Huge information was found at field level and internet.

\section{RESUlT}

Table 1. Mortality rates (death rate /year/1,00000, data for 2002)

\begin{tabular}{|c|c|c|}
\hline Diseases & Male & Female \\
\hline cardiovascular diseases & 259.3 & 278.4 \\
\hline stroke & 85.4 & 95.6 \\
\hline respiratory infections & 63.5 & 63.8 \\
\hline HIV/AIDS & 46.2 & 43 \\
\hline suicide, violence, war & 37 & 14.9 \\
\hline tuberculosis & 32.9 & 17.3 \\
\hline lung cancer & 28.4 & 11.4 \\
\hline diabetes mellitus & 14.1 & 17.7 \\
\hline stomach cancer & 16.7 & 10.5 \\
\hline cirrhosis of liver & 16.1 & 9.1 \\
\hline colorectal cancer & 10.3 & 9.7 \\
\hline breast cancer & 0.1 & 15.3 \\
\hline esophageal cancer & 9.1 & 5.2 \\
\hline alzheimer's disease and other dementia & 4.7 & 8.1 \\
\hline oral and oropharynx cancers & 7.1 & 3.1 \\
\hline leukemia & 4.7 & 3.8 \\
\hline asthma & 3.9 & 3.8 \\
\hline pancreatic cancer & 3.9 & 3.5 \\
\hline tetanus & 3.4 & 3.5 \\
\hline STDs & 2.9 & 2.9 \\
\hline bladder cancer & 4 & 1.7 \\
\hline meningitis & 2.9 & 2.7 \\
\hline syphilis & 2.7 & 2.3 \\
\hline malignant/neoplasm & 2.4 & 2.4 \\
\hline epilepsy & 2.2 & 1.8 \\
\hline hepatitis B & 2.3 & 1 \\
\hline parkinson's disease & 1.6 & 1.6 \\
\hline melanoma/skin cancer & 1.1 & 1 \\
\hline & & \\
\hline & & \\
\hline & & \\
\hline & & \\
\hline & & \\
\hline
\end{tabular}




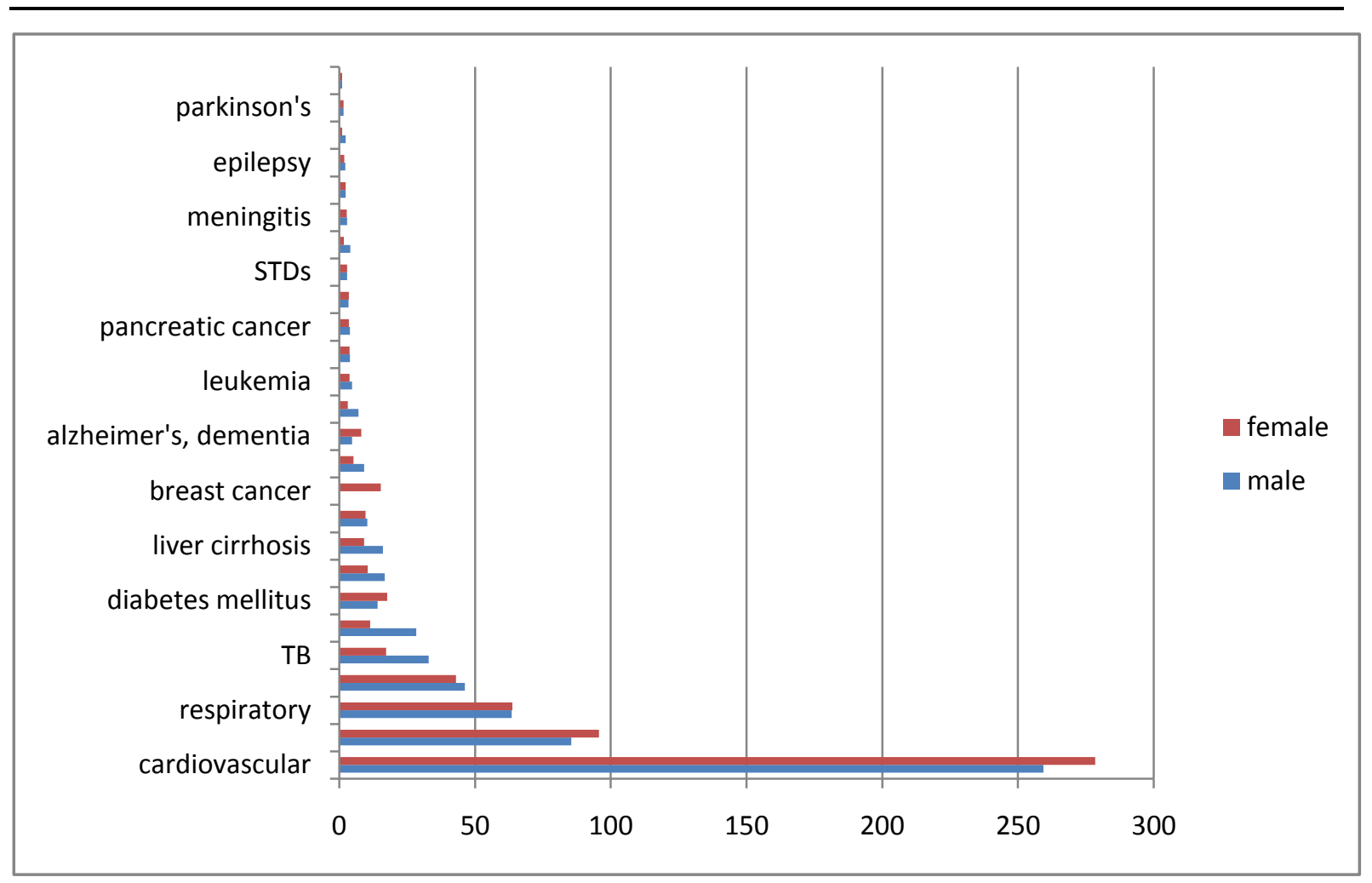

Table 2. Top 10 countries with healthy diet and life expectancy

\begin{tabular}{|c|c|c|c|c|}
\hline Rank & Country & Staple food & Death rate & Life expectancy \\
\hline 1 & Japan & rice & 9.38 & 83.7 \\
\hline 2 & Singapore & rice & 3.42 & 83.1 \\
\hline 3 & China & rice & 7.7 & 76.1 \\
\hline 4 & Sweden & potato & 9.45 & 82.4 \\
\hline 5 & France & bread with baguette & 9.06 & 82.4 \\
\hline 6 & Italy & wheat & 10.1 & 82.8 \\
\hline 7 & Spain & rice & 9.8 & 82.3 \\
\hline 8 & South Korea & rice & 5.54 & 82.5 \\
\hline 9 & Israel & $\begin{array}{c}\text { chickpea, bean, } \\
\text { doughnut }\end{array}$ & 11 & 81 \\
\hline 10 & Greece & $\begin{array}{c}\text { vegetables, fish, egg, } \\
\text { chicken }\end{array}$ & \multicolumn{2}{c|}{} \\
\hline
\end{tabular}

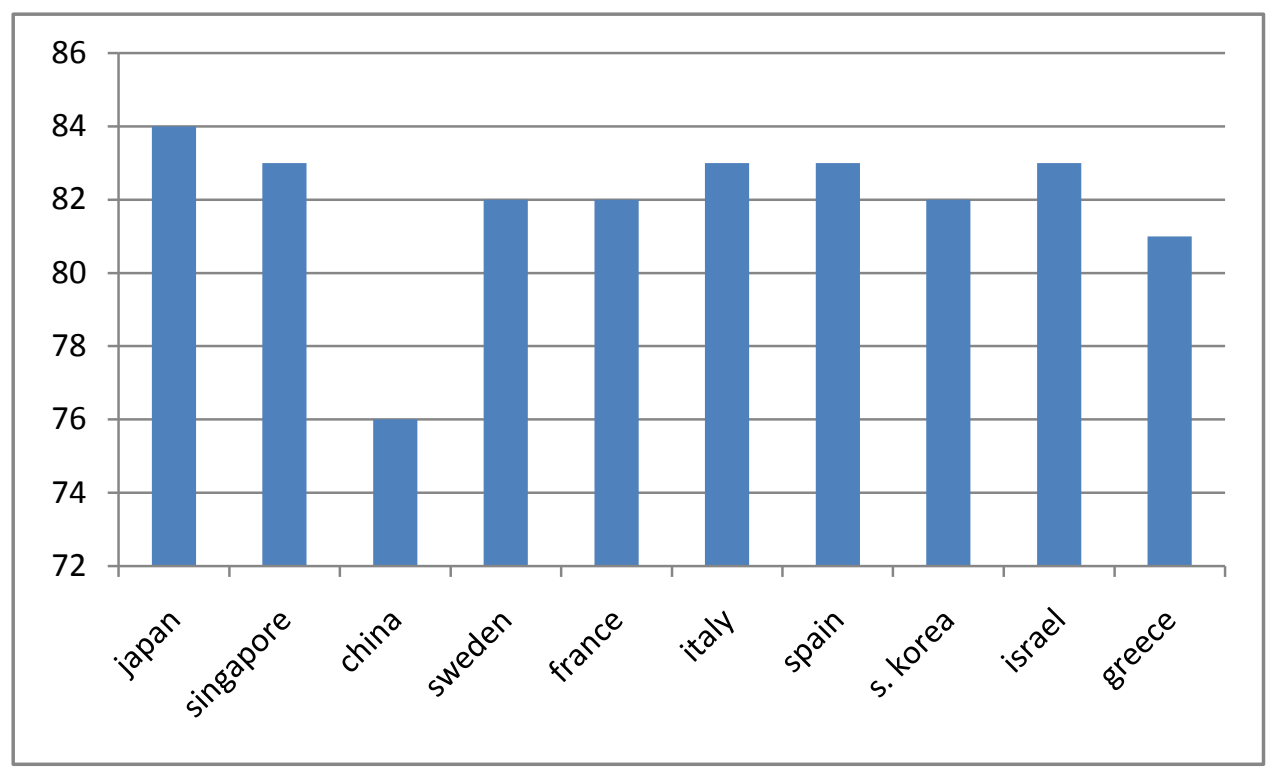


Table 3. Seasonal fruits and vegetables

\begin{tabular}{|c|l|l|}
\hline Month & \multicolumn{1}{|c|}{ Fruits } & \multicolumn{1}{|c|}{ Vegetables } \\
\hline January & lemon, papaw & cabbage, cauliflower \\
\hline February & lemon, papaw & cauliflower \\
\hline March & pineapple, mango & cauliflower, lettuce \\
\hline April & pineapple, mango & pea, cauliflower, lettuce \\
\hline May & pineapple & okra, pea, cauliflower, lettuce \\
\hline June & melon, blueberry, peach, strawberry & corn, lettuce \\
\hline July & melon, blueberry, peach, strawberry, plum & cucumber, tomato, corn, lettuce, green bean \\
\hline August & melon, blueberry, peach, strawberry, plum & $\begin{array}{l}\text { cucumber, tomato, corn, egg plant, lettuce, } \\
\text { green bean }\end{array}$ \\
\hline September & pomegranate & eggplant, pumpkin, tomato, spinach, lettuce \\
\hline October & pomegranate, grape & $\begin{array}{l}\text { pumpkin, cauliflower, spinach, lettuce, sweet } \\
\text { potato }\end{array}$ \\
\hline November & pear, pomegranate & $\begin{array}{l}\text { pumpkin, sweet potato, cauliflower, } \\
\text { mushroom, spinach }\end{array}$ \\
\hline December & pear, papaw, pomegranate & sweet potato, mushroom, cauliflower \\
\hline
\end{tabular}

\section{Best time to eat fruit}

Eat fruit on an empty stomach: Eating fruit with meals is the cause of bloating, diarrhea and discomfort is equally misleading. Eating fruit with a meal can slow the emptying of your stomach but only by a small amount. This is actually a good thing as it may help you feel fuller and cut back on calories. Eating fruit before or after a meal: If you eat fruit before or after a meal, the nutrients will somehow be lost. Our digestive system is more than prepared to digest and absorb the nutrients from fruit, whether it's eaten on an empty stomach or with a meal. Diabetic patient should eat fruit 1-2 hours before or after meal: For the majority of diabetics, eating fruit on an empty stomach isn't great advice. Pairing fruit with a meal or snack is usually a better choice. Best time of day to eat fruit is the afternoon: Our metabolism slows down in the afternoon and eating a food that's high in sugar, such as fruit, raises your blood sugar levels. The truth is that there's no harm in eating fruit in the morning. Fruit is healthy any time of the day. Want to lose weight: Due to the fiber in fruit, eating it may help you feel full for longer. This could cause you to eat fewer calories and may even help you lose weight. Have gestational diabetes: Like for those with type 2 diabetes, eating fruit with a meal is probably a good choice. However, if you have trouble controlling your blood sugar, avoiding fruit in the morning may help.

Table 4. GI values can be interpreted as percentages on an absolute scale

\begin{tabular}{|c|c|l|}
\hline Classification & GI & \multicolumn{1}{c|}{ Examples } \\
\hline Low GI & 55 or less & $\begin{array}{l}\text { bean, small seeds, whole grain, most vegetables, most sweet fruits, } \\
\text { mushroom, chili }\end{array}$ \\
\hline Medium GI & $56-69$ & white sugar, banana, sweet potato, grape \\
\hline High GI & 70 and above & white rice, white potato, white bread \\
\hline
\end{tabular}

Table 5. Lifespan of various animals in captivity and wild

\begin{tabular}{|c|c|c|c|}
\hline Animals & Food habit & Lifespan in captivity & Lifespan in wild \\
\hline giant tortoise & herbivore & 255 & 150 \\
\hline elephant & herbivore & 80 & 70 \\
\hline hare & herbivore & 12 & 4 \\
\hline cow & herbivore & 25 & 22 \\
\hline goat & herbivore & 22 & 20 \\
\hline giraffe & herbivore & 36 & 8 \\
\hline spotted deer & herbivore & 22 & 20 \\
\hline peacock & omnivore & 30 & 12 \\
\hline hyaena & carnivore & 24 & 13 \\
\hline tiger & carnivore & 20 & 10 \\
\hline black bear & frugivore & 30 & 15 \\
\hline rhesus monkey & herbivore & 40 & 15 \\
\hline giant panda & herbivore & 25 & 6 \\
\hline pigeon & graminivore & 15 & 45 \\
\hline chimpanzee & herbivore & 55 & \\
\hline
\end{tabular}


Relation among Food Habit, Morbidity and Mortality

\begin{tabular}{|c|c|c|c|}
\hline \hline gorilla & herbivore & 50 & 38 \\
\hline gibbon & herbivore & 45 & 33 \\
\hline orang utan & herbivore & 60 & 40 \\
\hline fresh water crocodile & carnivore & 100 & 45 \\
\hline fruit bat & insectivore & 22 & 9 \\
\hline cobra & carnivore & 32 & 20 \\
\hline
\end{tabular}

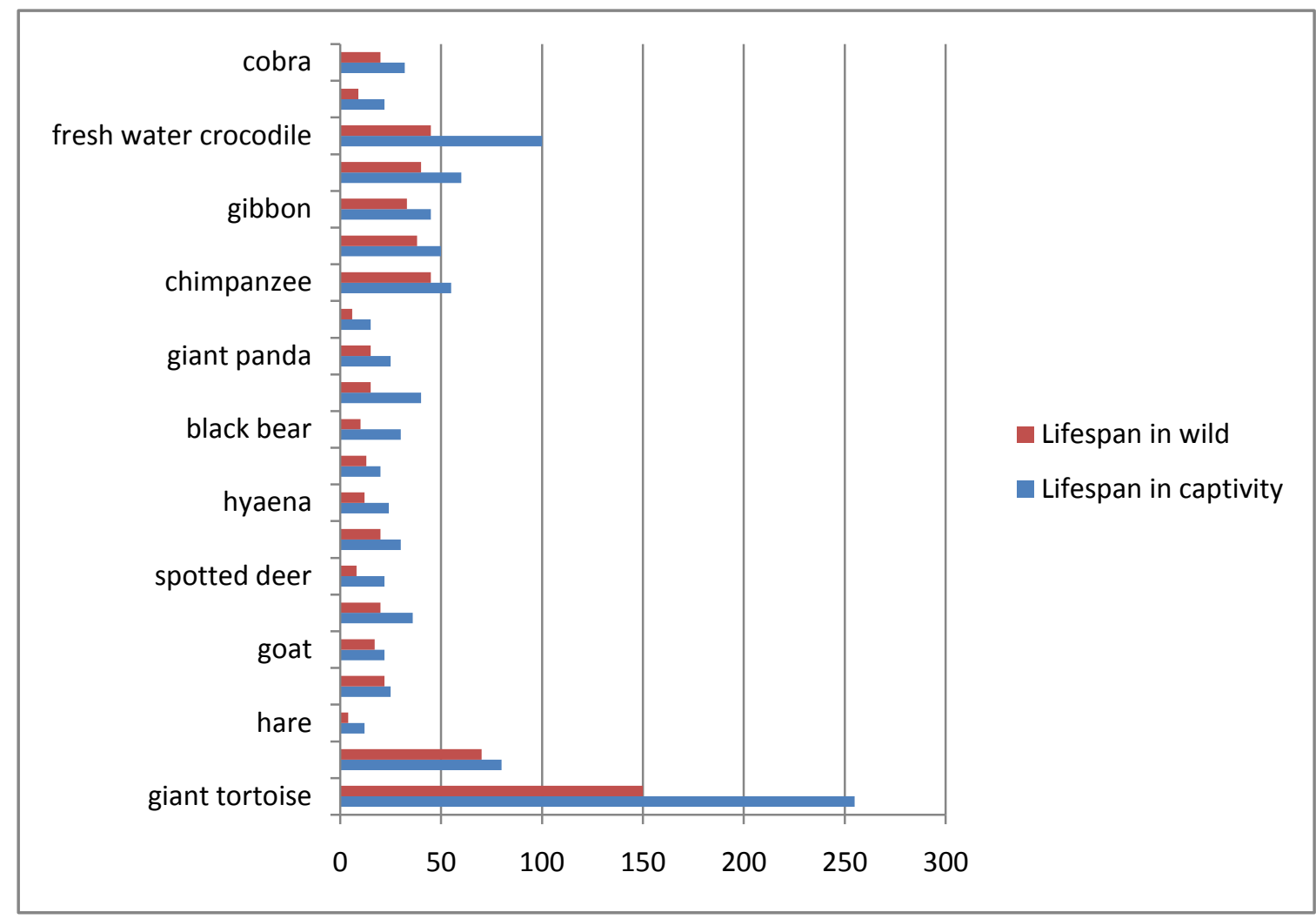

\section{Longevity in animals}

A 255-year-old giant tortoise named Adwaitya died at the Calcutta Zoo. Desert animals tend to get quite old before they die. Some animals invest their time and energy in having lots of babies; others use their resources to live longer. An animal might live long by the presence of little predators or if foods are available. Armored beasts like turtles, armadillos, and beetles can protect themselves from the predators. Flying animals also seem to have an advantage; bats last much longer than rodents, perhaps they can escape predators more easily. Very poisonous animals can last a long time. As an island species, it has enjoyed natural protection from predators over the course of its history. Larger animals tend to live longer than small ones. Animals with larger brains and which are more social it longer lives. Social insects have more longevity than the lonesome varieties. Some flies last only a couple of days, while a termite queen can survive for 30 years (Daniel Engber).

Table 6. Top ten women with higher lifespan with their lifestyle

\begin{tabular}{|c|c|c|c|c|}
\hline Name & $\begin{array}{l}\text { Age at } \\
\text { death }\end{array}$ & $\begin{array}{c}\text { Place of } \\
\text { death/Residence }\end{array}$ & Food & Exercise \\
\hline Jeanne Calment & 122 & France & $\begin{array}{l}\text { coffee with milk, rusk, fry, } \\
\text { braised beef, chocolate, fruit } \\
\text { salad, banana, orange, spicy } \\
\text { food, sweet after every meal }\end{array}$ & long prayer \\
\hline Sarah Knauss & 119 & US & not found & not found \\
\hline Lucy Hannah & 117 & US & not found & not found \\
\hline Marie-Louise Meilleur & 117 & Canada & not found & not found \\
\hline Violet Brown & 117 & Jamaica & not found & not found \\
\hline Emma Morano & 117 & Italy & raw egg, cooky & not found \\
\hline Misao Okawa & 117 & Japan & $\begin{array}{c}\text { ramen noodles, sushi } \\
\text { (Japanese traditional food) }\end{array}$ & sleep \\
\hline Nabi Tajima & 116 & Japan & sushi (Japanese traditional & sleep \\
\hline
\end{tabular}




\begin{tabular}{|c|c|c|c|c|}
\hline & & & food) & \\
\hline Maria Capovilla & 116 & Ecuador & not found & not found \\
\hline Susannah Mushatt Jones & 116 & US & egg, grit, bacon & not found \\
\hline
\end{tabular}

A yogic diet can improve your body, mind, and spirit. For maximum benefit, combine these dietary suggestions with asana (physical postures), pranayama (breathing techniques), and meditation.

\section{Yogic Diet}

1. Fruits of all types, especially those that are naturally sweet

2. All vegetables, except onions and garlic

3. Whole grains, especially oats, wheat, and rice

4. Beans, tofu, mung, aduki

5. Plant-based oils, like sesame, sunflower, and olive oil

6. Nuts and seeds

7. Natural, raw sugar, maple, molasses

8. Herbal teas, water with lemon/lime

9. Sweet spices, like cinnamon, cardamom, mint, basil, turmeric, ginger, cumin, fennel

\section{Avoid food during yoga}

1. Meat and fish of all types, including eggs

2. Processed /artificial foods, junk food, artificial sweeteners, soda

3. Animal fats

4. Fried foods

5. Canned foods, except naturally canned tomatoes and fruit

6. White flour, white sugar

7. Garlic, onions, spicy foods

8. Stale and overly cooked foods

9. Microwaved foods

10. Alcohol and tobacco

11. Foods that are genetically engineered

All dangers are caused by the ignorant. No danger comes from the wise. The powers of mind are desires; its seed is ignorance. Soul as the foam in the ocean sometimes arises and again disappears. So I have seen the universe come and go (The Goal of the Yogi. Levitation also Creation of Universe). For properly building our body we need carbohydrate $70 \%$ from whole grain, $20 \%$ protein from pulses and $10 \%$ oil from bran oil, nut oil or other good sources. We need to follow international dish which is called my plate which is 8 inches square and $1.5-2$ inches deep. The Indonesian man who claimed to be 146 years old - the longest living human ever - has died in his village in Central Java. According to his papers, Sodimedjo, also known as MbahGhoto (grandpa Ghoto), was born in December 1870. Hindu monk Swami Sivananda was born on August 8, 1896, according to his passport. He is now applying to Guinness World Records to verify his claim. It currently lists Japan's Jiroemon Kimura, who died in June 2013 aged 116 years and 54 days, as the oldest man to have ever lived. He has a simple and disciplined life. He also added that he eats very simple- only boiled food without oil or spices, rice and boiled lentil stew with a couple of green chilies. He said he used to perform a two-hour yoga session in Kolkata. He would avoid milk and fruits because these are fancy foods.

Table 7. Sleep record of wild animals

\begin{tabular}{|c|c|c|}
\hline Animal & Sleep record & Lifespan \\
\hline koala & 19 & 16 \\
\hline lemur & 16 & 18 \\
\hline sloth & 20 & 25 \\
\hline hippopotamus & 17 & 45 \\
\hline panda & 10 & 20 \\
\hline lion & 19 & 10 \\
\hline
\end{tabular}




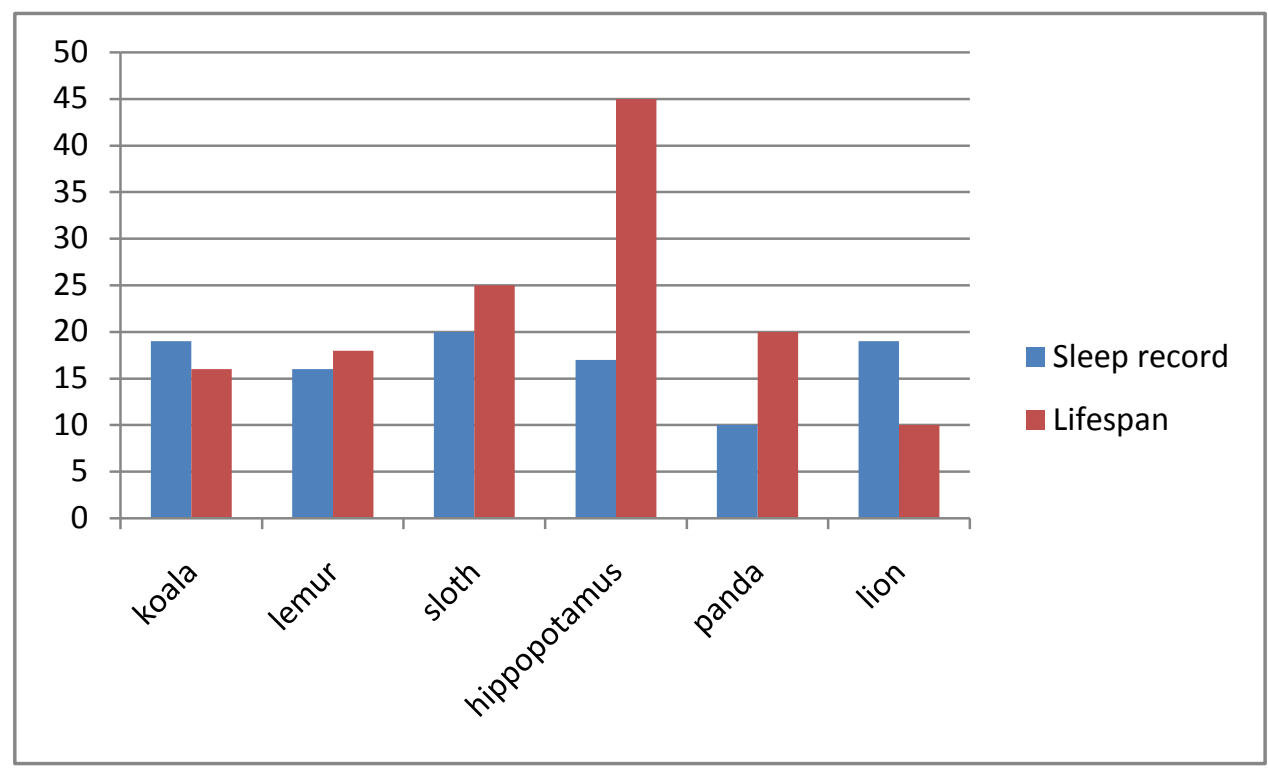

\section{DISCUSSION}

Ram Dev, India: Daily 1 hour kapalbhati is important to reduce midribs, waist and thigh fats. We should take first meal of the day with our satisfaction, second is $2 / 3$ portion of the first meal and third will $1 / 3$ portion of first meal. We should take maximum fruits, vegetables, pulses, bread and minimum rice. Refined oil and sugar is always bad for health. Eat reddish gud and minimum chili. If you feel hungry eat groundnuts (imported peanuts carry allergen). In nature except for nocturnal beings like owl, bat and some carnivores no living being eats after sunset. This intake cannot be digested and converted poison. Only $13 \%$ nutrients are retained in pulses if we prepare in a pressure cooker (no sunlight no air circulation), without pressure cooker this is $87 \%$ and we get $97 \%$ in earthen pots. Aluminium coking or serving pots create poisons that affect health. We should change pulses regularly. Soya Bean (soybean) is complex proteins which human body can't digest. It is basically a food for pigs/ livestock for meat in Europe and USA. US produce $98 \%$ of soybean. It is promoted as a health food in third world countries like India. Food takes within 48 minutes of preparation. Frozen and reheating food is always discarded. Teel or groundnut oil alternatively for two-three months at a stretch is good. Yogic jogging for 15 minutes daily is good for health.

Shilpa Shetty, India: While consuming 1800 calories in a day now, Shilpa begins her day with amla or aloe vera juice. She takes brown rice, brown pasta, brown sugar, brown bread etc. Shilpa cooks wholesome foods such as salmon, turkey, veggies etc. in olive oil. After having strenuous workout session, Shilpa consumes protein shake, eight black raisins, and two dates. She practices yoga for two days, strength training for another two days, and cardio for one day. She has further divided her strength training workouts into upper and lower body workouts. In strength training, instead of being reliant on light weights, she banks on heavy weights to shape up her muscles. She also meditates for ten minutes after yoga to wash out stress. She also recommends for her fan to take almond milk, nut butter, organic coffee, flax meal and mustard oil.

Jackie Chan, Hong Kong: Low in fat, low in sodium and low in carbs, and he also made sure to eat loads of protein to help with muscle building. If Jackie eats ice cream or steak, just add 20 minutes to his workout routine later in the day. Bodyweight exercises each day, such as finger tip and thumb press up, splits, back bends, deep knee squats, one legged squats, stretching and some acrobatic leaps, jogging 3-5 miles a day for his cardio and doing 5 sets of 10 push ups and 5 sets of 20 sit ups each day. Now in his 50's (with bum ankles from breaking them in past films), he only jogs 1 hour a day, and has modified his workout routine to help him stay in the best shape possible, but not in severe way. He also uses exercise machines and uses a treadmill in 2 hour intervals, 3 times a week. And he prefers to use free weights, which is a weight-lifting style that's much more popular in the martial arts world. And lastly, one of the easiest workouts Jackie does 20 minutes brisk walk each day.

Bruce Lee, China: Bruce Lee preferred Chinese or other Asian dishes, oyster, shrimp or chicken with vegetables and tofu. For Bruce Lee, the larger amounts of rice, noodles and vegetables often used in 
Chinese food are filled with more high-energy carbohydrates than western food portions that favor more fat and protein. Although his diet mainly consisted of Chinese food, he was also fond of steak and, for a time, ate liver once a week.

Dwayne Johnson (Rock), USA: As a bodybuilder he always maintain a 22-week diet chart which is full of bunch of egg whites, filet mignon, chicken, fish, oatmeal, broccoli, asparagus, baked potato, cream of rice, salad and complex carbs. He maintains the ratio of protein, carbohydrate and fat.

Homo sapiens originated from H. erectus from east Africa (Foley 2003). Human had been differed from their languages (Tomaselo 2003). Human nutrition needs are similar to other animals need (Schmidt-Nielsen 1996). Human had great tendency to eat many more vegetables than meat. Animals were consumed more than vegetables or at least in the same amounts of vegetables (Cordain 2002). In Paleolithic period they took $30 \%$ animal and $70 \%$ vegetable origin when they live in tropical areas (eg. the Kung), or they might feed if they lived in cold regions where vegetables were scarce (Ungar and Teaford 2002; Ungar 2007). Nuts have greater role for brain development than meat. Around 1000 years ago agriculture was first discovered in southwest Asia. The rearing of animals also facilitated the human effort to survive in fixed locations (Diamond 2001). Food problem caused diseases after 40 and poor feeding habit created problems to our future generations (Kaati et al. 2002). Diabetes mellitus, high blood pressure not easily found in children who have strong strength and higher aerobic power (Cordain 2002). Lack of physical exercise and ingestion of excess calorie are to enhance obesity (Neel 1962). Ideal proportion of vegetable and meat for human is 3:1 (Milton 1999, 2000). Human took animals' milk 5500-6000 years ago when they pet cat and dog. Paleolithic people didn't take milk. $75 \%$ peoples of the world not to take milk for lactose. Wild animals contain only $4 \%$ lipid where domestic animals have 25-30\%. Higher carbohydrates are found in plant root which rich in starch and fiber. Fruits were seasonal and meat depended on hunting, so it was not easy to take more meat (Zucoloto 2011).

\section{CONCLUSiON}

Human tongue bears four types of taste buds- sweet, bitter, salt and sour. Among these only sweet is our pleasant taste and others are unpleasant. Sour is evolutionarily significant as it is a sign for a food that may have gone rancid due to bacteria. Acidic food stimulates the taste buds and enhances flavor. Pure salt is regarded as highly unpleasant. Historically salt has long been used as a meat preservative for water excretion. Umamiis newly invented taste, has a long tradition in Asian cuisine. It is characterized as savory, meaty, and rich in flavor. Salmon and mushroom are food with umami taste. Most animals' red meat carries low density lipoprotein (LDL) which is caused for cardiovascular diseases and it shows world's maximum death-rate. Birds' meat and fishes are with white meat which is not bad. Sea fishes carry essential omega-3/6 fatty acid which is good for antioxidant but we should remember that large fishes are equivalent to meat and prawn/shrimp carries huge bad cholesterol. Animal origin (meat, fish, egg, milk) are very favorite in most people. All dangerous diseases like bird flu from bird, swine flu from swine, HIV from monkeys, duck plague from duck, mad cow from cow, cancers from red meat and malaria, sleeping sickness or other diseases are come from mosquito. Otherwise, excess taking of glucose from rice, bread or fruits may be occurred diabetes mellitus. Every research indicates that plants are better than animals as human food. Harvard school of medicine has been proposed 101 advice for longer life- Goal, Time, Control anger, Group work, Overextended, Stress relief, Unbearably tense, Pessimistic, Conflict with others, Burned out, Feeling lonely, Mental break, Breathing, Countdown slowly, Body scan, Massage, Imagery, Meditation, Mindful eating, Social bond, Always change lunch, Reasonable pace, Envision a happy outcome, Expect lapses, Live in a gray zone, Accept the change, Don't wait to write, Get the details, Size of food, Healthy eating plate, Natural food, Go for novelty, Balanced diet, Stay hydrated, Protein portion will be small, Take two times fish in a week, Avoid impulse eating, Healthy eating away from home, Grocery store, Don't shop on an empty stomach, Get organized, Comparison shopper, Label-savvy, Foods and nutrients to increase, Food components reduce, Sensible breakfasts, What's for lunch, Salad, What should you snack on, More fruits and vegetables, Easy dinners, Frequent but small meal, don't overeat, Avoid crash diet, Use caffeine, Limit alcohol, Drink water, Aerobic activity, Strength training, Yoga, Rhythmic repetitive activity, Go outside, Safe stretch, Heel-to-toe walk, Single leg stance, Reducing risk of falls, Fall proof your home, Better night's sleep, Cognitive behavioral therapy, All-natural sex tips, Comfortable sex, Conscious on food which causes heartburn, Self-help for heartburn, Herbal alternatives, Conscious your bladder training, Fecal incontinence, Eliminate 
food which cause diarrhea, Check cholesterol, Improve cholesterol profile, Control blood pressure, How to lower blood pressure, Lose weight, Alcohol in moderation, Men (pathological test), Women (pathological test), Control headache, Explore alternative treatment, Physical therapy, Muscle aches, Tackle pain with exercise, Helpful gadgets if hand pain, Develop back healthy habits, Good mattress, Know he laws of lifting, Learn proper stretching, Diabetes test, Follow diabetic diet, Know your blood sugar symptoms, Keep busy and engaged, Stay connected, Keep moving, Go Mediterranean. So, it's clearly proven that if anybody maintain good lifestyle with good food and exercise he/she will be better which will lead longer life.

\section{REFERENCES}

Cordain L. 2002. The paleo diet: lose weight and get healthy by eating the food you were designed to eat. New York: Wiley.

Diamond J. 2001. Armas, germs e aco. Riode Janeiro: Record.

Foley R. 2003. Oshumanos antes da humanidade. Sao Paulo: UNESP.

Kaati G, Bygren LO and Edvinsson S. 2002. Cardiovascular and diabetes mortality determined by nutrition during parents' and grandparents'. Slow growth period. European Journal of Human Genetics 10, 682-688.

Milton K. 1999. A hypothesis to explain the role of meat-eating in human evolution. Evolutionary Anthropology 8: $11-23$.

Milton K. 2000. Hunter-gatherer diets: a different perspective. American Journal of Clinical Nutrition 71: 665667.

Neel JV. 1962. Diabetes mellitus: a 'thrifty' genotype rendered detrimental by 'progress'? American Journal of Human Genetics 14: 353-362.

Schmidt-Nielsen K. 1996. Fisiologia Animal ( $5^{\text {th }}$ edition). Sao Paulo: Santos.

Tomaselo M. 2003. Origins culturais da aquissicao do conhecimento. Sao Paulo: Martins Fontes.

Ungar PS and Teaford MF. 2002. Human diets: its origin and evolution. Westport: Bergin and Garvey.

Ungar PS. 2007. Evolution of the human diet: the known, the unknown, and the unknowable. Oxford: Oxford University Press.

Zucoloto FS. 2011. Evolution of the human feeding behavior. Psychology and Neuroscience 4(1): 131-141. DOI:10.3922/j.psns.2011.1.015

Citation: M. A. Kabir, " Relation among Food Habit, Morbidity and Mortality ", International Journal of Research Studies in Zoology, vol. 3, no. 3, p. 23-32, 2017. http://dx.doi.org/10.20431/2454-941X.0303004

Copyright: () 2017 Authors. This is an open-access article distributed under the terms of the Creative Commons Attribution License, which permits unrestricted use, distribution, and reproduction in any medium, provided the original author and source are credited. 